\title{
Can Analyst Tracking Be Able to Curb Violations of Chinese Listed Companies?
}

\author{
Xiao Zhang ${ }^{1}$, Yi Wang ${ }^{1}$ \\ ${ }^{1}$ School of Finance, Zhongnan University of Economics and Law, Wuhan, Hubei, 430070
}

Keywords: Analyst follow; company violations; corporate governance

\begin{abstract}
This paper takes China's 2007-2016 A-share listed company as a research sample and uses Probit and Bivariate Probit estimation methods to study the relationship between analyst tracking and company violations. The study found that analysts track the impact of corporate violations on two sides, and analyst tracking effectively curbed corporate violations; however, when a company violates regulations, analyst tracking reduces the probability of a company being audited. The conclusions of this paper indicate that the role of analyst governance in China's capital market has certain limitations.
\end{abstract}

\section{Introduction}

In the 20 years of the development of China's capital market, the repeated violations of listed companies have become a major "stubborn disease" that infringes upon the legitimate rights and interests of investors and disrupts the order of the capital market. The data shows that there were 4,457 violations in China from 2000 to 2016, and the number of violations increased from 29 in 2000 to 566 in 2016. In 2016, the CSRC strictly supervised, and a total of 183 cases were punished, and 218 administrative punishment decisions were made, with unprecedented supervision. In view of the "stubborn disease" of the company's violations, how to "recover the root disease" is worthy of deep thought and study. The Chinese company system started late, and the development of the company's internal governance mechanism needs to be improved. This has led to the emergence of various corporate governance issues, such as corporate fraud, large shareholders' encroachment on the interests of small and medium investors, and capital markets and small and medium investors. Caused damage. In recent years, the academic community has found that external factors such as media, securities analysts, and product market competition can play the role of externally supervised corporate governance. These external governance factors can improve the company's external governance environment and effectively compensate for the shortcomings of internal governance. It is of great significance to protect the legitimate rights and interests of small and medium-sized investors and promote the healthy development of the capital market.

As an external corporate governance mechanism, can an analyst effectively play a role in supervising governance and protecting the legitimate interests of investors? In the case that the capital market is not fully effective, there is an information asymmetry between the company and the investor. There is a dual agency problem between the shareholders and the management, between the major shareholders and the minority shareholders. The analyst is an important issue. Information brokers can alleviate information asymmetry and agency problems by analyzing and communicating company fundamentals (Jensen and Mecking, 1976). As the reform of China's capital market accelerates, it is of great significance to explore the role of analysts in supervising the behavior of listed companies.

This paper draws on the estimation methods adopted by Poirier (1980), Lu Yao et al. (2012) in the study of corporate violations, and breaks down the company's violations into two processes: violation tendency and violation inspection. The Probit and Bivariate Probit models are used to explore the analysts. The impact of corporate violations and violations. 


\section{Second, theoretical analysis and hypothesis proposed}

\subsection{Analyst and company's tendency to violate regulations}

Jensen and Mecking (1976) argue that analysts can mitigate information asymmetry in capital markets and reduce agency costs by mining and transmitting company information, which is an important external regulator. Compared with ordinary investors, analysts have better information mining and understanding capabilities, a more professional industry background, and can actively obtain more company information by actively communicating with company management and major shareholders, and conducting company research activities. The company's anomalous activities can be discovered in a timely manner (Yu, 2008; Wiesenfeld et al., 2008), thus providing valuable investment advice to investors (Dyck et al., 2010). This paper argues that in the case of China's capital market information asymmetry is still relatively high, analysts act more as information mediators and play a supervisory effect, so the following assumptions are made:

Hypothesis 1: The more the number of analysts tracking, the lower the tendency of listed companies to violate the rules.

Hypothesis 2: Compared with listed companies without analyst tracking, there are analysts tracking the tendency of listed companies to have lower violations.

\subsection{Analyst and company violation inspection}

As far as the Chinese capital market is concerned, analysts tend to publish optimistic research reports (Wu Chaopeng et al., 2013). As a good analyst, not only must have independent analytical skills, but also do a good job in the service of institutional investors and listed companies. In order to maintain good relations with listed companies, analysts will try to avoid publishing. Violation information that has a material adverse effect on the company. In the long run, analysts can gain more company information by maintaining relationships with listed companies (Zhang Xuelan and He Dexu, 2008). At the same time, the analyst industry is fiercely competitive. Some of them have used the seller analyst profession as a springboard to accumulate resources and then turn to the fund and other buyer organizations for employment. These private interests will also prompt analysts to try their best to conceal the company's violations. More importantly, in China, when stocks rise, analysts can gain profits through investors. Because China's short selling mechanism is underdeveloped, investors rarely profit from falling stock prices. Analysts naturally have no incentive to reveal. The company's violations. In summary, the following assumptions are made:

Hypothesis 3: The more the analysts track the number, the lower the probability that the listed company's violations will be exposed by the audit.

Hypothesis 4: Compared to a listed company that is not tracked by analysts, the probability that a listed company tracked by an analyst will be exposed by the audit after being violated.

\section{Research design}

In this paper, all A-share listed companies from 2007 to 2016 were selected as research samples. After removing the financial industry and deleting the missing sample data of key variables, we obtained unbalanced panel data with 16439 observations. Winsorize processing was performed on continuous variables at the $1 \%$ and $99 \%$ levels. The data in this paper comes from the CSMAR database and the RESSET database, and uses Stata software for related data processing.

Using Poirier (1976), Lu Yao et al. (2012), Wan Liangyong, etc. (2014), the Bivariate Probit model was used to study the influence of analysts on company violations, and the Probit model was used for comparison to ensure the robustness of the research results. . First set the model $(1$,$) using$ the Probit method for regression, where Zit indicates company violations. The models (2a) and (2b) were set up and a more detailed study was carried out using the Bivariate Probit method, where Ana represents the analyst tracking variable and was replaced with $\ln A$ na and ISAna when estimated.

Z_it $=\beta \_0+\beta \_1$ Ana $+\beta \_2$ shrcr5 $+\beta \_3 \quad$ pNdir $+\beta \_4$ pinddir $+\beta \_5$ lnassets $+\beta \_6$ Return $+\beta \_7$ pstateshr $+\beta \_8$ Auditor4 $+\beta \_9$ TobinQ $+\beta_{-} 10$ A3Growthrate $+\beta \_11$ lev $+\beta \_12$ AvgDtrdTurnR $+\beta \_13$ 
Volatility $+\varepsilon \operatorname{it}(1)$

Fraud_it ${ }^{\wedge *}=\beta \_F 0+\beta \_F 1 \quad$ Ana $+\beta \_F 2$ shrcr5 $+\beta \_F 3 \quad p N d i r+\beta \_F 4$ pinddir $+\beta \_F 5$ lnassets $+\beta \_F 6$ Return $+\beta$ F_F pstateshr $+\beta$ F F Auditor $4+\mu$ it (2a)

Detect $\mathrm{it}^{\wedge *}=\beta \_\mathrm{D} 0+\beta \_\overline{\mathrm{D}} 1 \quad$ Ana $+\beta \_\mathrm{D} 2$ TobinQ $+\beta \_\mathrm{D} 3 \quad$ A3Growthrate+ $\beta \_\mathrm{D} 4 \quad$ lev $+\beta \_\mathrm{D} 5$ AvgDtrdTurnR $+\beta$ _D6 Volatility $+\beta \_D 7$ pstateshr $+\beta \_D 8$ Auditor4+v_it (2b)

\subsection{Variable selection and model setting}

Variable selection

(1) Company violation variables

In this paper, the dummy variable Vio is used to measure the violation of the listed company. If the company is disclosed in the year, there is a violation of the fact that Vio=1, otherwise it is 0 . The violation of the facts here refers to corporate violations in a broad sense, including the violations of listed companies themselves, as well as violations by listed company leaders.

(2) Analyst tracking variables

The analysts in this paper refer to brokerage analysts (seller analysts). This article uses the number of analyst teams that have tracked and analyzed the company in the past to measure the company's AnaAttention, and the model is logarithm. On this basis, the dummy variable ISAna is generated, indicating whether the company has tracked by the analyst team in the current year, and then it is 1 , otherwise it is 0 .

(3) Control variables

Drawing on the research of Lu Yao et al. (2012), Khanna et al. (2014) and Wan Liangyong (2014), this paper sets two groups of control variables that are not identical. Among them, the control variables for corporate irregularity include: equity concentration (shrcr5), board size (pNdir), independent directors (pinddir), company size (lnassets), stock annual return (Return), state-owned shareholding ratio (pstateshr), auditor type (Auditor4). The control variables for company audits are: Tobin Q, A3Growthrate, lev, tradable turnover (AvgDtrdTurnR), stock return volatility (Volatility), state-owned Shareholding ratio (pstateshr), auditor type (Auditor4).

Table 1 lists the descriptive statistics for the main variables in this paper. In all of the samples, the average value of company violations (Vio) was 0.13 , and an average of 13 companies per 100 A-share listed companies violated regulations and were audited. The average value of AnaAttention is 6.93, which means that an average of 6.93 teams per company are tracking and analyzing. The average value of the latent variable ISANA is 0.74 , indicating that the average annual analyst team's coverage of listed companies is as high as $74 \%$. .

Table 1 Descriptive statistics of variables

\begin{tabular}{ccccccc}
\hline variable & Number of observations & Mean & Standard deviation & Minimum value & median & Maximum \\
\hline Vio & 16439 & 0.13 & 0.33 & 0 & 0 & 1 \\
\hline AnaAttention & 16439 & 6.93 & 8.95 & 0 & 3 & 65 \\
\hline lnAna & 16439 & 1.46 & 1.14 & 0 & 1.39 & 4.19 \\
\hline ISAna & 16439 & 0.74 & 0.44 & 0 & 1 & 1 \\
\hline
\end{tabular}

\subsection{Analysis of regression results}

Analyst tracking and company violations

Table 2 shows the empirical results of analysts' tracking of the impact of corporate violations. Among them, the (1) column and the (2) column use the Probit estimation method as the estimation result of the model (1). The results show that analysts track the number of analysts, whether the analysts have a negative impact on the company's violations, that is, the analyst tracking can play an external supervision role to prevent the company's violations, the impact is significant at $1 \%$ level, verified Assumption 1.

Columns (3) and (4) use the Bivariate Probit estimation method as the estimation results for models (2a) and (2b). When the independent variable is lnAna, the regression result in column (3) shows that the regression coefficient between the number of analyst followers and the company's tendency to violate (Fraud) is negative and is significant at the level of 1\%, indicating that for the 
company, The more analysts track the number, the less likely a company is to break the rules, and the analyst can play a depressing role; the number of analyst tracking and the regression coefficient of the company's violation check (Detect) is significantly negative, indicating that for companies that have violated regulations, analysts The more the number of tracking, the less likely the violations are checked by the regulatory authorities. This result shows that the analysts have covered the facts of the company's violations for their own interests and increased the difficulty of being exposed by the audit. This hypothesis is verified. . When the independent variable is whether there is an analyst follow (ISAna), the regression coefficient obtained is also negative, the impact on the violation tendency is significant at the level of $10 \%$, and the impact on the violation inspection is significant at the level of $1 \%$. It shows that compared with companies without analyst tracking, the companies that are tracked by analysts are less prone to violations, and the probability of being audited after violations is lower. It is very good to verify hypothesis 2 and hypothesis 4 of this paper. The results in Table 2 show that in the Chinese capital market, the analyst's supervision of corporate violations has two sides. On the one hand, analysts can suppress the tendency of listed companies to violate the rules; on the other hand, analysts have also reduced the company's violation of the facts being audited. The probability of arrival.

Table 2 Impact of analyst tracking on company violations

\begin{tabular}{|c|c|c|c|c|c|c|}
\hline \multirow[b]{2}{*}{ variable } & \multirow{2}{*}{$\frac{(1)}{Z}$} & \multirow{2}{*}{$\frac{(2)}{Z}$} & \multicolumn{2}{|c|}{ (3) } & \multicolumn{2}{|c|}{ (4) } \\
\hline & & & Fraud & Detect & Fraud & Detect \\
\hline \multirow{2}{*}{$\ln A n a$} & $-0.079 * * *$ & & $-0.145^{* * *}$ & $-0.085^{* * *}$ & & \\
\hline & $(-5.80)$ & & $(-3.76)$ & $(-5.26)$ & & \\
\hline \multirow{2}{*}{ ISAna } & & $-0.113^{* * *}$ & & & $-0.150 *$ & $-0.149 * * *$ \\
\hline & & $(-3.65)$ & & & $(-1.81)$ & $(-3.82)$ \\
\hline Control variable & $\mathrm{Y}$ & $\mathrm{Y}$ & $\mathrm{Y}$ & $\mathrm{Y}$ & $\mathrm{Y}$ & $\mathrm{Y}$ \\
\hline Number of observations & 16439 & 16439 & 16439 & 16439 & 16439 & 16439 \\
\hline Wald chi2 & 367.913 & 347.388 & 388.780 & & 345.682 & \\
\hline $\mathrm{p}>$ chi2 & 0.000 & 0.000 & 0.000 & & 0.000 & \\
\hline Log likelihood & -6120.0 & -6130.3 & -6086.5 & & -6104.7 & \\
\hline
\end{tabular}

\subsection{Robustness test}

The conclusions of this paper may be plagued by endogenous problems, that is, analysts suppress the company's tendency to violate the rules, while companies with low violation rates may also attract analysts' attention; analysts reduce the probability of violation audits, and the lower the probability of violations being audited The company has attracted analysts to follow up. Therefore, this paper lags the independent variable in the first phase to carry out endogenous control on the regression results, and checks whether the analyst tracking variables of the previous period have an impact on the current company violations. Table 3 shows the regression results considering the analyst's hysteresis effect. Regardless of whether the Probit estimation method or the partially observable Bivariate Probit estimation method, the number of analysts and whether the analyst tracks the regression coefficient of the lag term is significantly negative, indicating that the previous article was obtained. The conclusion is steady.

Table 3 Impact of analyst tracking (lag) on company violations

\begin{tabular}{|c|c|c|c|c|c|c|}
\hline & $(1)$ & $(2)$ & \multicolumn{2}{|c|}{ (3) } & \multicolumn{2}{|c|}{ (4) } \\
\hline variable & $\mathrm{Z}$ & $\mathrm{Z}$ & Fraud & Detect & Fraud & Detect \\
\hline \multirow{2}{*}{ L.lnAna } & $-0.066 * * *$ & & $-0.146 * * *$ & $-0.075 * * *$ & & \\
\hline & $(-4.34)$ & & $(-3.18)$ & $(-4.35)$ & & \\
\hline \multirow{2}{*}{ L.ISAna } & & $-0.076 * *$ & & & $-0.172 *$ & $-0.114 * * *$ \\
\hline & & $(-2.20)$ & & & $(-1.68)$ & $(-3.05)$ \\
\hline Control variable & $\mathrm{Y}$ & $\mathrm{Y}$ & $\mathrm{Y}$ & $\mathrm{Y}$ & $\mathrm{Y}$ & $\mathrm{Y}$ \\
\hline Number of observations & 13238 & 13238 & 13238 & 13238 & 13238 & 13238 \\
\hline Wald chi2 & 267.570 & 253.453 & 285.563 & & 254.639 & \\
\hline $\mathrm{p}>$ chi2 & 0.000 & 0.000 & 0.000 & & 0.000 & \\
\hline Log likelihood & -4968 & -4975.1 & -4931.5 & & -4945.5 & \\
\hline
\end{tabular}




\section{Conclusions and recommendations}

Based on the research samples of all A-share listed companies in China from 2007 to 2016, this paper examines the relationship between analyst tracking and company violations by using the partially observable Bivariate Probit estimation method and Probit estimation method. After controlling the relevant variables, the study found that the impact of analyst tracking on corporate violations has two sides. On the one hand, analyst tracking can effectively suppress the company's tendency to violate regulations; on the other hand, it reduces the probability of company violations being audited. This conclusion is still robust after controlling endogeneity and changing analyst proxy variables. This conclusion reveals the limitations of the role of analyst governance.

The conclusions of this paper provide empirical evidence for China's regulatory authorities to govern corporate violations, investors' investment decisions, and to promote the healthy development of the analyst industry. First of all, for the regulatory authorities, on the one hand, we must encourage the healthy development of the analyst industry and give full play to their governance functions; on the other hand, we must also guard against the collusion between analysts and listed companies, deceive the regulatory authorities, and damage the small and medium-sized investors. Legal rights. For analysts, it is necessary to further improve research capabilities and broaden research ideas. In the case that the regulatory authorities improve supervision and analysts strengthen self-discipline, analysts will play an important role in improving the efficiency of financial supervision, protecting the legitimate interests of small and medium investors, and promoting the healthy development of the capital market.

\section{References}

[1] Lu Yao, Zhu Yujie, Hu Xiaoyuan. Empirical research on institutional investors' shareholdings and listed company's violations [J]. Nankai Management Review, 2012, (01): 13-23.

[2] Wan Liangyong, Hu Wei. Network location, independent director governance and company mergers and acquisitions - empirical evidence from Chinese listed companies [J]. Nankai Management Review, 2014, (02): 64-73.

[3] Xu Nianxing, Jiang Xuanyu, Yi Zhihong, Xu Xinzhong. Analyst conflict of interest, optimistic bias and stock price collapse risk [J]. Economic Research, 2012, 07:127-140.

[4] Chen J. , Cumming D. , Hou W. Et al. Does the External Monitoring Effect of Financial Analysts Deter Corporate Fraud in China? [J]. Journal of Business Ethics, 2016, 134: 727-742.

[5] Dale J. , Poirier. Partial Observability in Bivariate Probit Models [J]. Journal of Econometrics, 1980, 12(2): 209-217.

[6] Degeorge F. Ding Y. Jeanjean T. , Stolowy H. Analyst Coverage, Earnings Management and Financial Development: An International Study [J]. Journal of Accounting \& Public Policy, 2013, 32(1): 1-25.

[7] Dyck A. , Morse A. ,Zingales L. Who Blows the Whistle on Corporate Fraud? [J]. Journal of Finance, 2010, 65(6): 2213-2253.

[8] Graham J. , C. Harvey, S. Rajgopal. The economic implication of corporate financial reporting [J]. Journal of Accounting and Economics, 2005, 40(1-3), 3-73.

[9] Jensen M. C. , Meckling W. Theory of the firm: Managerial Behavior, Agency Costs and Ownership Structure. [J]. Journal of Financial Economics, 1976, 55(1): 81-106. 